\title{
From bedlam to bioethics: Where did my psychodramatic childhood lead me?
}

A meeting of two: eye to eye, face to face. And when you are near I will tear your eyes out and place them instead of mine, and you will tear my eyes out and will place them instead of yours, then I will look at you with your eyes and you will look at me with mine.

— J.L. Moreno, Invitation to an Encounter, 1914

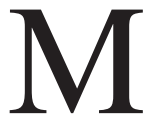
y father was the psychiatrist J.L. Moreno (1889-1974), the pioneer of psychodrama, group psychotherapy and sociometry, the forerunner of modern social network analysis. I tell the story of his work and influence in my new book, Impromptu Man: J.L. Moreno and the Origins of Psychodrama, Encounter Culture, and the Social Network. ${ }^{1}$

An early critic of his medical school lecturer Sigmund Freud, who he believed reduced people's legitimate creative aspirations to neuroses, J.L. began his career in Vienna where he established a reputation as the founder and director of the "Theatre of Spontaneity," the site for his discovery of Peter Lorre and Elisabeth Bergner, and as the editor of a literary journal called Der Daimon, which published Heinrich Mann, Martin Buber, Franz Werfel, Peter Altenberg and various other notables. Somehow, he also managed to write a series of influential expressionist manifestos, serve as a medic in wartime refugee camps, found a home for displaced persons, organize a self-help group for sex workers, complete medical school, design a new stage for his productions, coinvent an early version of audiotape and practise medicine in a spa town outside of Vienna. He emigrated to the United States in 1925.

Once in New York, J.L. took about ten years to obtain the support to purchase his Beacon Hill Sanitarium in 1935 , where he put in place his program of psychodrama therapy - the

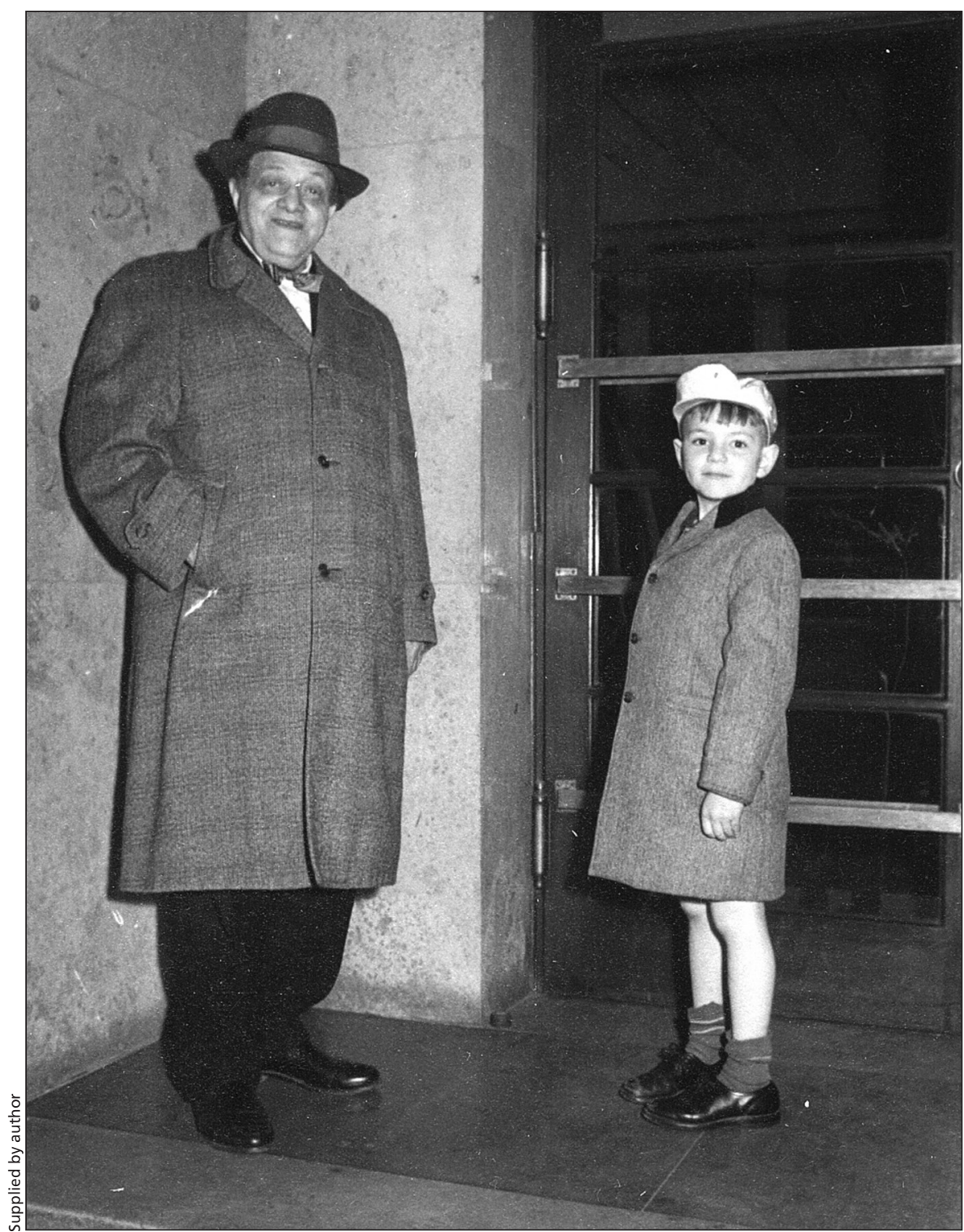

The author with his father.

systematic use of role playing to explore and resolve interpersonal conflicts - and from which he engaged in the energetic and relentless promotion of his ideas for the next 40 years. In the intervening years, he introduced the term "group therapy" into the literature and engaged in classic social network studies at Sing Sing prison, at a state reform school for girls and at public schools in Brooklyn. President Franklin Roosevelt recruited him to help with his Depression-era resettlement program, and his ideas about role playing and spontaneity were applied to the training of intelligence operatives dur- 
ing World War II. In the 1930s, he became a social science celebrity, well known for predicting the outcomes of heavyweight title fights for the Associated Press based on his social psychological assessment of the boxers and their training camps. Never wrong in his predictions, J.L. was perhaps the first media "mental expert."

But for all his charisma, J.L.'s virtues were his vices. Over the years, his self-promotion, eccentric manner, the-

his public psychodrama sessions in Manhattan attracted members of the Actors Studio and young comedians like Alan Alda and Woody Allen. As interesting and exciting as my career as a professor of bioethics has been, the sheer uniqueness of my childhood set a high bar for the next two score and ten years. J.L. was fascinated and preoccupied with the role of God; in that sense, siring a prophet would have been a very satisfactory result.

\section{What I do cherish from my unusual childhood was the way J.L. embraced even the most disturbed patients in all their humanity.}

atrical displays (like his psychodramatic trial of Jack Ruby at the American Psychiatric Association in $1964^{2}$ ) and insistence on his own priority in the history of psychotherapy and social science alienated as many as they attracted. Yet leading psychiatrists like William Alanson White and Karl Menninger encouraged him, and many mental hospitals introduced psychodrama therapy. His favorite patients were the ones with paranoid delusions. Perhaps his most famous case was that of a Manhattan butcher during World War II who insisted he was the real Adolf Hitler. For months, J.L. conducted him in role plays of the Führer's inner circle, finally bringing his behavior under a measure of control.

That was nearly 10 years before I was born in 1952, when my father was 63 years old. Looking back, I can say that growing up on the grounds of J.L.'s small mental hospital, observing his innovative approach to psychiatry and what he called interpersonal relations and coming to know so many visionaries, scientists, scholars and oddballs who were attracted to him and his ideas, made the first 20 years of my life truly extraordinary. For 25 years,
Nonetheless, 41 years after my father's death, I can report that I didn't become a prophet and that any emotional problems I have suffered are well within one standard deviation of the human norm. My family and close friends often comment on how "normal" I seem, everything considered. Does that mean that psychodramatic child rearing is the way to go or that I got lucky and nature prevailed over an unusual nurture? I have no idea. But the question has often preoccupied me.

What I do cherish from my unusual childhood was the way J.L. embraced even the most disturbed patients in all their humanity. In those days, before there were many antipsychotic medications and when long-term hospital admissions were not uncommon, he identified with the underlying needs that all of us have for love and acceptance. Several times, senior psychiatrists who saw his psychodrama demonstrations early in their careers have told me they have never seen anyone who loved his patients more than J.L. did.

For much of his last decade, J.L. saw his ideas cannibalized by popular culture. Encounter groups and new popular therapies captured the media attention he had enjoyed for so long. Social network analysis was characterized by elaborate computations in professional journals rather than applied to institutional reform. Sometimes he grew angry and paranoid, even lashing out at those he believed took his ideas piecemeal without crediting him. It was a personality problem of which he was acutely aware. "There is no controversy about my ideas," he wrote in 1953, "they are universally accepted. I am the controversy."

Believing that human problems could not be solved on an individual basis nor solely in the consulting room or clinic, J.L. advocated a new discipline. "Sociatry" would treat human beings in their concrete context, in homes and workplaces and in the streets, as previous religion and science had initially tried but finally failed to do. It took me some time after I started working as a hospital ethicist to realize how much that notion had influenced me, that so much of our modern concern with ethics is not only a testament to conflicting moral values, but an expression of existential disorientation. As Nietzsche had it, "since Copernicus, man has been rolling from the center toward X." ${ }^{4}$

I wish I could be as confident as J.L. was that humankind will finally find a sense of direction. But at least I can say that he left me with the idea that we could.

\section{Jonathan D. Moreno PhD}

Department of Medical Ethics \& Health Policy, University of Pennsylvania, Philadelphia, Pennsylvania

\section{References}

1. Moreno JD. Impromptu man: J.L. Moreno and the origins of psychodrama, encounter culture, and the social network. New York: Bellevue Literary Press; 2014

2. The Kennedy round. Time Magazine 1964;May 15.

3. Moreno JL. Who shall survive? New York: Beacon House; 1953:108.

4. Nietzsche F. The will to power [Translated by Kauffman W and Hollingwood RJ]. Walter Kaufmann, editor. New York: Vintage;1968:8.

CMAJ 2015. DOI:10.1503/cmaj.141235 